\title{
Preface: New Solutions Mitigating Environmental Noise Pollution
}

\author{
Gaetano Licitra ${ }^{1, *(D)}$ and Konstantinos Vogiatzis ${ }^{2}$ (D) \\ Department of Earth Sciences, University of Pisa, Via Santa Maria, 53, 56126 Pisa, Italy \\ 2 Department Civil Engineers, University of Thessaly, 38334 Volos, Greece; kvogiatz@uth.gr \\ * Correspondence: g.licitra@arpat.toscana.it
}

Received: 30 October 2019; Accepted: 1 November 2019; Published: 6 November 2019

\section{Introduction}

The increasing attention of the public towards the effects of noise pollution on health pushed the EU to issue the Environmental Noise 49/2002/CE Directive. A revision in 2017 [1], 15 years after its original publication, remarked how noise continues to be a major issue compromising people's health and leading to effects such as cardiovascular and hypertension diseases and ischemic heart disease, learning impairments, sleep disturbance, and annoyance [2-4]. The mandatory noise mapping phase brought to light an enormous number of citizens annoyed by noise sources like road and railway traffic and airports [5]. Owners of agglomerations and infrastructures were asked to mitigate noise deriving from transport and industrial sources, both inside and outside buildings.

Thus, the overall exposure to noise must be reduced and unwanted sound should be avoided by means of wide prevention. When not possible, mitigation solutions must be undertaken to fulfill with noise action plans, most of the time leading to the installation of acoustic barriers that are not always welcome by citizens. As a counterpart, the scientific community is moving towards new acoustic solutions that also look at green economy [6], recycling [7], new approaches to traffic management such as low emission zones [8], new pavements [9], new and sustainable vehicles and tires [10], and novel systems to reduce noise at sources for railways [11] and airports [12]. Methods and procedures are set to establish the efficacy and efficiency of mitigation actions; standards on barriers and pavement can qualify performance, and the prioritization of actions has become crucial in order to guarantee transparent principles for the public.

The present Special Issue determines the state-of-the-art on noise mitigation at the source, but also for the propagation path and at the receivers. For these reasons, authors were invited to submit their works about noise action plan, transportation noise mitigation, policies and good practices for traffic management, noise planning, noise control, industrial noise remediation, methods for action prioritization, evaluation of mitigation action performance, models and algorithms for source characterization and outdoor sound propagation, classification, evaluation and protection of quiet areas, noise mitigation in building acoustics, wind turbine noise, use of recycled and waste materials to reduce noise.

\section{Highlights}

The EU Environmental Noise Directive requesting noise maps puts high demand on the access, availability, and integration of numerous data and geographical information. Furthermore, higher data quality is linked to better results. After nearly 20 years of experience, new approaches or upgrades are emerging in order to improve the noise mapping phase.

In the framework of the Life+ 2013 program, the DYNAMAP project aims to facilitate and accelerate the noise mapping process by means of an automatic monitoring system, composed of 
low-cost sensors and a powerful software platform. Benocci, et al. [13] reported an application along the ring road of Rome of this "real-time" noise mapping project, providing a real picture of the noise generated by vehicular traffic. The accuracy and reliability of the system have been tested with a monitoring campaign and satisfactory results have been achieved, showing an average overall prediction error of $\sim 1.5 \mathrm{~dB}$.

Not all kind of noise is considered in the maps; thus, Alsina-Pagès et al. [14] studied different types of anomalous noise events present in the street in order to characterize them, for both soundscape and maps integration. The analysis has been performed considering both the Signal-to-Noise Ratio and the duration of the anomalous events to evaluate their presence in urban areas in Andorra.

Noise maps are also needed to evaluate and preserve sensitive receivers and quite areas. However, due to the particular characteristics, hospitals are usually located close or within urban agglomerations and they can be exposed to high levels of environmental noise. Montes-González, et al. [15], presented a study of one of the main hospitals in the Extremadura region (Spain) aiming to assess the acoustic impact of outdoor sound sources. Long and short-term measurements were carried out and a software model was developed, finding that noise impact is primarily influenced by road traffic, cooling towers, and emergency helicopters, but their importance depends on the facade under consideration. Given that the overall situation of the hospital needs to be improved, the authors suggested a series of solutions for mitigating the noise impact on sensitive areas.

Noise mitigations become necessary where noise maps report limit exceedances.

Noise barriers are the most common solution chosen to mitigate road traffic noise. Given their diffusion on the territory, every improvement to this technology would have a major effect in terms of exposure reduction or cost production and environmental impacts. In this context, Zannin et al. [16] evaluated the effectiveness of barriers using artificial neural networks combined with the design of experiments. Aiming to determine the influence of the coefficient of absorption of the barrier material and the barrier height on sound attenuation and on the formation of acoustic shadows, the authors found that the absorption coefficient strongly influences the noise attenuation provided by noise barriers, while barrier height is correlated with the formation of larger areas of acoustic shadow. The methodology proposed by the authors can also be applied to more complex systems without loss of generality, confirming that artificial neural networks can be tools for assessing acoustic barrier efficiency based on an investigation into the sensitivity of the system's controlled variables.

However, conventional noise barriers see their net insertion loss reduced by the well-known effects of diffraction at the edges and reflections. Furthermore, their acceptance rate is reduced by limitations on the field of view, natural light, and airflow. The evolution of research on the subject led to the development of sonic crystals as noise barriers. Fredianelli et al. [17] reviewed the latest studies concerning the practical application of sonic crystal as noise barriers, with a specific focus on the integrations of Bragg's law properties with other mitigation effects such as hollow cylinders, wooden or recycled materials, or porous coating. These are all solutions that increase the insertion loss and frequency bandgap, while inserting the noise mitigation action in a green and circular economy. The paper also discussed the pros and cons of sonic crystal barriers, searching for the actual viable best solution, while also stimulating future research on the aspects requiring improvement.

Another common and very effective solution for mitigating road traffic noise is laying low emission pavements. Therefore, studying the mixture parameters and their durability is very important to achieve good acoustic performance [18]. Inside the LIFE SOUNDLESS project, Morcillo, et al. [19] created a selection of mixes where some waste materials were used. The best mixtures were selected not only according to traditional mechanical parameters but also others, such as damping and dynamic stiffness. Furthermore, the acoustic performances of pavements using this asphalt were assessed several times with the close proximity (CPX) and statistical pass by (SPB) methods to evaluate the performance durability. The results showed a decrease of $3 \mathrm{~dB}$ to $7 \mathrm{~dB}$ in noise produced.

In any case, selecting the most appropriate pavement for a given noise reduction objective can be a difficult task. Thus, Bérengier et al. [20] proposed a simple method to evaluate the noise impact of a 
pavement in typical road geometries and environmental conditions. The approach relies on a database of measurements of emission spectra of road vehicles on several typical pavements and on a database made of pre-calculations of noise propagation for typical road configurations. An interactive web tool (DEUFRABASE, version 3, Ifsttar, Strasbourg, France) allows then to estimate noise levels for various pavements and road configurations as functions of the traffic flow and composition. The tool has been validated trough measurements and, even if it is still limited to a low number of pavements and with several simplifications, it can predict the noise impact of typical road configurations with errors most often less than $2 \mathrm{~dB}$.

Not only road traffic noise is addressed by the European noise directive, but railway, airport, and industrial noise are dealt with. In fact, Gerolymatou, et al. [21] performed environmental noise measurements and simulations, mapping population exposure to noise around a Greek airport. Moreover, a survey campaign and a soundscape analysis were conducted. In this way, the impact of aircraft movements on both local residents' and tourists' perceptions of soundscapes and possible health effects by using the WHO's DALY (Disability Adjusted Life Year) metrics were assessed. The combined results could yield possible evaluation tools for noise management.

The noise produced by ports in their surroundings has been neglected for far too long, until Bernardini et al. [22] acoustically characterized different small vessels at various speeds that move in ports. Short and long-term measurements were performed and a map of noise generated by vessels moving in Livorno's canals was produced and validated. The number of citizens exposed was also estimated, together with the number of highly annoyed people. Different scenarios, such as different vessel speeds, limited flow, restricted areas or new residential areas were studied in order to prevent citizen exposure to noise and possible complaints about small boats.

Overall, the papers published in this Special Issue of Environments focused on noise mapping and mitigation action for all the major sources reported by the EU noise directive not forgetting to mention a source that is affecting citizens in modern society: leisure noise. Asensio et al. [23] started with the assessment of this kind of noise through a monitoring campaign in Málaga and with programmed communication actions, aimed to raise awareness among stakeholders and to support the planning and prioritization of further noise mitigation actions. The long-term noise indicators were analyzed, as well as the time-based patterns of noise. The results showed high noise levels higher than $60 \mathrm{~dB}$ in the leisure areas at night, confirming that the subject is deserving attention and monitoring.

Conflicts of Interest: The authors declare no conflicts of interest.

\section{References}

1. European Commission. Report from the Commission to the European Parliament and the Council on the Implementation of the Environmental Noise Directive in Accordance with Article 11 of Directive 2002/49/EC; European Commission: Brussels, Belgium, 2017.

2. Douglas, O.; Murphy, E. Source-based subjective responses to sleep disturbance from transportation noise. Environ. Int. 2016, 92, 450-456. [CrossRef] [PubMed]

3. Van Kempen, E.; Babisch, W. The quantitative relationship between road traffic noise and hypertension: A meta-analysis. J. Hypertens. 2012, 30, 1075-1086. [CrossRef] [PubMed]

4. Muzet, A. Environmental noise, sleep and health. Sleep Med. Rev. 2007, 11, 135-142. [CrossRef] [PubMed]

5. Licitra, G.; Ascari, E.; Brambilla, G. Comparative analysis of methods to estimate urban noise exposure of inhabitants. Acta Acust. United Acust. 2012, 98, 659-666. [CrossRef]

6. Lacasta, A.M.; Penaranda, A.; Cantalapiedra, I.R.; Auguet, C.; Bures, S.; Urrestarazu, M. Acoustic evaluation of modular greenery noise barriers. Urban For. Urban Green. 2016, 20, 172-179. [CrossRef]

7. $\mathrm{Xu}, \mathrm{X}$.; Wang, H.; Sun, Y.; Han, J.; Huang, R. Sound absorbing properties of perforated composite panels of recycled rubber, fiberboard sawdust, and high density polyethylene. J. Clean. Prod. 2018, 187, 215-221. [CrossRef]

8. Dablanc, L.; Montenon, A. Impacts of Environmental Access Restrictions on Freight Delivery Activities: Example of Low Emissions Zones in Europe. Transp. Res. Rec. 2015, 2478, 12-18. [CrossRef] 
9. Losa, M.; Leandri, P.; Licitra, G. Mixture design optimization of low-noise pavements. Transp. Res. Rec. 2013, 2372, 25-33. [CrossRef]

10. Vogiatzis, K.; Kopelias, P. Benefits and limitations toward a sustainable road environment during the years of economic recession. Int. J. Sustain. Dev. Plan. 2015, 10, 701-712. [CrossRef]

11. Vogiatzis, K.; Vanhonacker, P. Noise reduction in urban LRT networks by combining track based solutions. Sci. Total Environ. 2016, 568, 1344-1354. [CrossRef]

12. Gagliardi, P.; Teti, L.; Licitra, G. A statistical evaluation on flight operational characteristics affecting aircraft noise during take-off. Appl. Acoust. 2018, 134, 8-15. [CrossRef]

13. Benocci, R.; Bellucci, P.; Peruzzi, L.; Bisceglie, A.; Angelini, F.; Confalonieri, C.; Zambon, G. Dynamic Noise Mapping in the Suburban Area of Rome (Italy). Environments 2019, 6, 79. [CrossRef]

14. Alsina-Pagès, R.M.; Garcia Almazán, R.; Vilella, M.; Pons, M. Noise Events Monitoring for Urban and Mobility Planning in Andorra la Vella and Escaldes-Engordany. Environments 2019, 6, 24. [CrossRef]

15. Montes-González, D.; Barrigón-Morillas, J.M.; Gómez Escobar, V.; Vílchez-Gómez, R.; Rey-Gozalo, G.; Atanasio-Moraga, P.; Méndez-Sierra, J.A. Environmental Noise around Hospital Areas: A Case Study. Environments 2019, 6, 41. [CrossRef]

16. Zannin, P.H.T.; do Nascimento, E.O.; da Paz, E.C.; do Valle, F. Application of Artificial Neural Networks for Noise Barrier Optimization. Environments 2018, 5, 135. [CrossRef]

17. Fredianelli, L.; Del Pizzo, A.; Licitra, G. Recent developments in sonic crystals as barriers for road traffic noise mitigation. Environments 2019, 6, 14. [CrossRef]

18. Licitra, G.; Cerchiai, M.; Teti, L.; Ascari, E.; Fredianelli, L. Durability and variability of the acoustical performance of rubberized road surfaces. Appl. Acoust. 2015, 94, 20-28. [CrossRef]

19. Morcillo, M.A.; Hidalgo, M.E.; Pastrana, M.D.C.; García, D.; Torres, J.; Arroyo, M.B. Life Soundless: New Generation of Eco-Friendly Asphalt with Recycled Materials. Environments 2019, 6, 48. [CrossRef]

20. Bérengier, M.; Picaut, J.; Pahl, B.; Duhamel, D.; Gauvreau, B.; Auerbach, M.; Fortin, N. Deufrabase: A Simple Tool for the Evaluation of the Noise Impact of Pavements in Typical Road Geometries. Environments 2019, 6, 27. [CrossRef]

21. Gerolymatou, G.; Rémy, N.; Vogiatzis, K.; Zafiropoulou, V. Assessing Health Effects and Soundscape Analysis as New Mitigation Actions Concerning the Aircraft Noise Impact in Small-and Middle-Size Urban Areas in Greece. Environments 2019, 6, 4. [CrossRef]

22. Bernardini, M.; Fredianelli, L.; Fidecaro, F.; Gagliardi, P.; Nastasi, M.; Licitra, G. Noise Assessment of Small Vessels for Action Planning in Canal Cities. Environments 2019, 6, 31. [CrossRef]

23. Asensio, C.; Gasco, L.; De Arcas, G.; López, J.; Alonso, J. Assessment of Residents' Exposure to Leisure Noise in Málaga (Spain). Environments 2018, 5, 134. [CrossRef] 